\title{
SHARP BOUNDS FOR THE PSI FUNCTION AND HARMONIC NUMBERS
}

\section{NECDET BATIR}

Abstract. We establish several new bounds for the psi function $\psi$ and harmonic numbers $H_{n}$. For example, we prove that

$$
\gamma+\frac{1}{2} \log \left(n^{2}+n+c\right)<H_{n}<\gamma+\frac{1}{2} \log \left(n^{2}+n+d\right),
$$

where the constants $c=e^{2(1-\gamma)}-2=0.329302 \ldots$ and $d=1 / 3=0.3333 \ldots$ are the best possible, and

$$
\gamma+\frac{1}{2} \log \left(\frac{2 n+a}{e^{2 /(n+1)}-1}\right)<H_{n} \leqslant \gamma+\frac{1}{2} \log \left(\frac{2 n+b}{e^{2 /(n+1)}-1}\right),
$$

where $a=2$ and $b=e^{2-2 \gamma}(e-1)-2=2.0024 \ldots$ are the best possible constants. Our estimations give extremely accurate values for $\gamma$, and they improve some estimations for $\gamma$ deduced very recently by $\mathrm{C}$. Mortici.

Mathematics subject classification (2010): Primary: 11B83; Secondary: 11B73.

Keywords and phrases: Digamma function, psi functions, harmonic numbers, Euler's constant, gamma function, inequalities.

\section{REFERENCES}

[1] M. Abramowitz, I. A. Stegun, Handbook of Mathematical Functions with Formulas, Graphs and Mathematical Tables, Dover, New York, 1972.

[2] H. AlZER, Inequalities for the harmonic numbers, Math. Z., 267, 1-2 (2011), 367-384.

[3] H. AlZER, Sharp inequalities for the harmonic numbers, Expo. Math., 24 (2006), 385-388.

[4] N. BATIR, On some properties of the digamma and polygamma functions, J. Math. Anal. Appl., 328, 1 (2007), 452-465.

[5] N. BAtiR, Some new inequalities for the gamma and polygamma function, J. Inequal. Pure Appl. Math.(JIPAM), 6, 4 (2005), article 103, pp. 9.

[6] T. P. Dence, And J. B. Dence, A survey of Euler's constant, Math. Mag., 82, 4 (2009), 255-265.

[7] D.W. DeTemple, A quicker convergences to Euler's constant, Amer. Math. Monthly, 100, 5 (1993), 468-470.

[8] A. Elbert And A. Laforgia, On some properties of the gamma function, Proc. Amer. Math. Soc., 128, 9 (2000), 2667-2673.

[9] N. Elezovic, C. Giordano And J. PeCaric, The best bounds for Gautschi's inequality, Math. Inequal. Appl., 3, 2 (2000), 239-252.

[10] R. L. Graham, D. E. Knuth, and O. Patashnik, Concrete Mathematics, Addison Wesley, 1989.

[11] C. MorTiCI, Improved convergence towards generalized Euler-Mascheroni constant, Appl. Math. Comput., 215, 9 (2010), 3443-3448.

[12] C. MorTici, Approximations of the gamma function in terms of the digamma function, Appl. Math. Lett., 23 (2010), 97-100.

[13] C. MorTici, Optimizing the rate of convergence in some new classes of sequences convergent to euler's constant, Anal. Appl.(Singap), 8, 1 (2010), 99-107.

[14] C. MoRTICI, A quicker convergence toward the gamma constant with the logarithmic term involving the constant e, Carpathian J. Math., 26, 1 (2010), 86-91. 
[15] M. B. VILlaRINO, Ramanujan's harmonic number expansion into negative power of a triangular number, J. Inequal. Pure Appl. Math., 9, 3 (2008), article 89.

[16] R. M. Young, Euler's constant, Math. Mag., 75, 422 (1991), 187-190. 